\title{
LOGÍSTICA REVERSA DOS RESÍDUOS ELETRÔNICOS DO SETOR DE INFORMÁTICA: REALIDADE, PERSPECTIVAS E DESAFIOS NA CIDADE DO NATAL-RN
}

\section{REVERSE LOGISTIC OF ELETRICAL AND ELETRONIC EQUIPMENT WASTE FROM INFORMATION TECHNOLOGY SECTOR: REALITY, PERSPECTIVES AND CHALLENGES IN NATAL-RN, BRAZIL}

\author{
Lorena Albuquerque Adriano da Silva*E-mail: lorena albuquerque@yahoo.com.br \\ Handson Claudio Dias Pimenta* E-mail: handson.pimenta@ifrn.edu.br \\ Lucila Maria de Souza Campos ${ }^{* *}$ E-mail: lucila@deps.ufsc.br \\ * Universidade Federal do Rio Grande do Norte (UFRN) Natal, RN \\ ** Universidade Federal de Santa Catarina (UFSC), Florianópolis, SC
}

\begin{abstract}
Resumo: O presente trabalho tem como objetivo não só diagnosticar a situação do gerenciamento de resíduos de equipamentos eletroeletrônicos (REEE), oriundos do setor de informática (comércio varejista e empresas de assistência técnica) de Natal/RN, mas também analisar como essas empresas estão se preparando para as adequações impostas pela Política Nacional de Resíduos Sólidos - PNRS, sob a ótica da logística reversa. Trata-se de uma pesquisa quantitativa e descritiva, para a qual foi adotado um questionário estruturado com 23 variáveis analíticas, divididas em 4 grupos: (i) Nível de Consciência sobre os Resíduos de Equipamentos Eletroeletrônicos; (ii) Práticas de Gestão Ambientais; (iii) Gestão de Resíduos de Equipamentos Eletroeletrônicos; (iv) Caracterização das Empresas e Respondentes, o qual foi aplicado em 20 empresas do setor de informática da cidade de Natal/RN. As empresas apresentaram uma série de deficiências em infraestrutura, informação e articulação com fabricantes, o que pode ser justificado pelo fato de $65 \%$ da amostra confirmar que os clientes atribuem pouco ou nenhum interesse à gestão dos resíduos sólidos na empresa. Em relação ao destino final, apenas 35\% direcionam os resíduos eletrônicos para a reciclagem, proporcionando o fluxo dos resíduos por mercados secundários. Por outro lado, $60 \%$ da amostra se incluiu no grupo responsável pelo recolhimento e tratamento de resíduos eletrônicos e $40 \%$ das empresas apresentam o plano de gerenciamento implementado e/ou em manutenção. Com isso, foi observado que as empresas estão pouco atentas às propostas da lei de resíduos sólidos e aos impactos sobre elas. Assim, a ausência de planos de gerenciamento de resíduos eletrônicos dificulta o fomento da logística reversa e, consequentemente, a adequação da PNRS frente aos resíduos eletrônicos.
\end{abstract}

Palavras-chave: Resíduos de equipamento eletroeletrônicos. Logística reversa. Gerenciamento de resíduos sólidos.

Abstract: This study aimed to diagnose the situation of electrical and electronic equipment waste (WEEE) across the information technology sector (trade and technical assistance) from Natal (capital of Rio Grande do Norte State, Northeast of Brazil) from reverse logistic perspective as well as to analyze how these companies have been preparing for the adjustments demanded by new Brazilian law concerning the waste management (National Policy on Waste Management). This is a quantitative and descriptive study on which was adopted a structured questionnaire with 23 variables divided into four groups (i) the awareness level on WEEE, (ii) WEEE management, (iii) environmental 
management and (iv) profile of companies which was applied to 20 companies in the IT sector from Natal / RN. Concerning the results, it was observed that companies have experienced a huge number of deficiencies in infrastructure, information and articulation related to reverse logistic, which helps to explain the fact that $65 \%$ of the sample believed that customers are little or no interested in solid waste management issues in the company. Also in reference to the waste management, $35 \%$ throw away the WEEE for recycling, providing the waste stream by the secondary markets. In addition, $60 \%$ of the sample were included in the group responsible for collecting and treatment of WEEE and $40 \%$ of companies have implemented the management plan and / or maintenance. In conclusion, it was observed that some companies are little attentive to the waste law and its impact on their business. Thus, the logistic reverse and the compliance with WEEE management are hampered by lack of WEEE management plans.

Keywords: Electronic waste. Reverse logistics. Waste management.

\section{INTRODUÇÃO}

O segmento empresarial tem buscado o equilíbrio entre as relações ambientais e econômicas, de modo a aperfeiçoar seus produtos e serviços, visando a uma responsabilidade ambiental diferenciada $e$, consequentemente, a uma explícita vantagem competitiva no setor atuante. Isso ocorre devido ao cenário econômico-tecnológico que impõe às organizações a necessidade de mudanças contínuas no modo de operar e gerir seus negócios, para que se adaptem à nova realidade e se mantenham competitivas. Assim, mesmo que o objetivo principal da empresa seja o lucro, a função ambiental tem se tornado cada vez mais importante devido ao aumento da conscientização do consumidor e de seu crescente interesse pelos processos que cercam os produtos e serviços. (OLIVEIRA; SERRA, 2010).

Além disso, a função ambiental se apresenta através de ferramentas que propiciam o desenvolvimento e aplicação de tecnologias limpas. Diante disso, o esforço ambiental das empresas é um fator que afeta o desempenho e a competitividades das empresas, além de ajudar as organizações a cumprir com as regulamentações ambientais. (LÓPEZ-GAMERO, 2010).

Vale destacar, ainda, que as organizações produtivas devem assumir sua responsabilidade em face do ciclo de vida de seus produtos. Tal responsabilidade ocorre, de acordo com a atual Política Nacional de Resíduos Sólidos - PNRS (Lei 12305/2010), de forma compartilhada, por meio de um conjunto de atribuições individualizadas e encadeadas dos fabricantes, importadores, distribuidores e comerciantes, dos consumidores e dos representantes governamentais dos serviços 
de gerenciamento de resíduos sólidos tanto para minimizar o volume de resíduos e de rejeitos, bem como para reduzir os impactos causados à saúde humana e à qualidade ambiental decorrente do ciclo de vida dos produtos. Assim, a PNRS aponta a logística reversa como uma alternativa de se assumir a responsabilidade compartilhada do ciclo de vida de produtos, promovendo o retorno dos produtos, após o uso pelo consumidor.

A logística reversa compreende o gerenciamento do fluxo inverso dos produtos, após o consumo, abrangendo os processos de coleta, transporte, armazenagem, estoque e desmontagem, desde o ponto de consumo até o ponto de origem, com o objetivo de agregar valor aos resíduos e minimizar os impactos sobre o meio ambiente. (ROGERS; TIBBEN-LEMBKE, 1998).

Dentro deste contexto, a logística reversa se apresenta como alternativa para contornar o acúmulo de resíduos sólidos em aterros, diminuindo a inadequada disposição final e reintroduzindo o material passível de reuso/reciclagem no ciclo produtivo. Enfatiza-se que, no Brasil, de acordo com a Associação Brasileira de Empresas de Limpeza Pública e Resíduos Especiais (ABELPRE, 2009), a geração de resíduos, no ano de 2009, atingiu a quantidade de 57.011.136 de toneladas, sendo apenas $56,8 \%$ desses resíduos dispostos em aterros sanitários. Os demais foram dispostos inadequadamente em aterros controlados e lixões.

Entre esses resíduos sólidos urbanos gerados, destacam-se os Resíduos de Equipamentos Elétricos e Eletrônicos (REEE), tais como computadores, impressoras, celulares e televisores. A geração desses resíduos é potencializada por um modelo de consumismo, marcado por uma necessidade criada pela mídia, impulsionando o consumidor a adquirir, cada vez mais, novos produtos e substituílos com imensa rapidez. Segundo dados do relatório "Recycling - from e-waste to resources", desenvolvido pelo United Nations Environment Programme (UNEP, 2009), com relação ao descarte de resíduos de informática, somente no Brasil, há uma estimativa de mais de 120.000 toneladas anuais, sendo uma geração de 96.800 toneladas de computadores, 17.200 t de impressoras e 2.200 t de telefones móveis.

Destaca-se que algumas características dos resíduos eletroeletrônicos impedem que eles sejam tratados em conjunto com os demais tipos de resíduos, visto que apresentam componentes não biodegradáveis, por isso não podem ser 
destinados a aterros sanitários. Esses resíduos são caracterizados por uma composição variada que abrange metais ferrosos, metais não ferrosos, vidro, plástico e outros materiais. O ferro e o aço, por sua vez, são os materiais mais comumente encontrados em peso e correspondem a quase metade do peso total. Os plásticos são o segundo maior componente em peso, representando $21 \%$ dos REEE. Metais não ferrosos, incluindo metais preciosos, representam $13 \%$ do peso total dos equipamentos eletrônicos. (ONGONDO, 2011).

Enfatiza-se que a visão compartilhada do ciclo de vida dos materiais, instituída pela PNRS, é aplicada aos REEE, de modo que os fabricantes, importadores, distribuidores, comerciantes e consumidores possuem uma responsabilidade, devendo implementar sistemas de logística reversa no gerenciamento desses resíduos. Assim, mesmo as pequenas empresas que revendem os equipamentos eletrônicos ou as que realizam manutenção se vêem obrigadas a disponibilizar infraestrutura e canais tanto para o recolhimento quanto à destinação adequada dos produtos e resíduos pós-consumo.

Partindo deste cenário, o presente estudo é orientado pela seguinte questãoproblema: qual a situação do gerenciamento dos REEE do setor de informática de Natal e como as empresas estão se preparando para as adequações impostas pela PNRS, fazendo uso da ferramenta de logística reversa?

Buscando responder a questão-problema, o objetivo geral deste estudo consiste em não só diagnosticar a situação do gerenciamento de resíduos de equipamentos eletroeletrônicos oriundos do setor de informática (comércio varejista e empresas de assistência técnica) de Natal, mas também analisar como essas empresas estão se preparando para as adequações impostas pela PNRS, sob a ótica da logística reversa. Como objetivos específicos, destacam-se: conhecer o perfil ambiental das empresas de equipamentos eletroeletrônicos na cidade, no que tange ao aos requisitos legais atendidos e às práticas proativas de gestão ambiental; diagnosticar as práticas existentes de gerenciamento de resíduos de equipamentos eletroeletrônicos - fontes geradoras, forma de armazenamento, tratamento/disposição final; investigar a potencialidade do estabelecimento de canais reversos. 
Trata-se de uma pesquisa aplicada por meio de uma abordagem quantitativa e descritiva, já que procura determinar status, opiniões ou projeções futuras nas respostas obtidas, registrando e correlacionando fatos. (SILVA; MENEZES, 2001; RAMPAZZO, 2005).

\section{REVISÃO TEÓRICA}

\subsection{RESÍDUOS ELETROELETRÔNICOS}

Os resíduos perigosos e os REEE são, muitas vezes, considerados como frações problemáticas de resíduos sólidos urbanos. Se tratados incorretamente, por um lado, há um alto risco de exposição indesejável e a propagação de poluentes no meio ambiente e na sociedade. Por outro lado, a coleta seletiva adequada e a reciclagem de REEE, em particular, podem reduzir o esgotamento de recursos e uso de energia, já que essa fração de resíduos geralmente contém substâncias valiosas, tais como: ouro, prata, paládio e o índio (BERNSTAD, 2011).

Quanto à geração de resíduos eletroeletrônicos no Brasil, a FEAM (2009) afirma que há uma previsão de acúmulo de REEE de sete milhões de toneladas (Tabela 1), entre os anos de 2001 e 2030. Tal geração é alarmante, visto que o país não tem controle adequado sobre os resíduos domésticos e, muito menos, sobre os resíduos eletrônicos. A posição do Brasil em relação ao destino final dos resíduos sólidos no Brasil apresenta a seguinte situação: no ano de 2009, 56,8\% foram destinados a aterros sanitários; $23,9 \%$ a aterros controlados e 19,3\% a lixões. (ABELPRE, 2009).

Contribuindo para a intensa geração de REEE, pode-se constatar no estudo da Associação Brasileira da Indústria Elétrica e Eletrônica (2010) que o mercado brasileiro, no primeiro semestre de 2010, apresentou uma comercialização de PCs que chegou a 6,2 milhões de unidades. Em comparação com o mesmo período do semestre passado (que atingiu 5,1 milhões de computadores), houve um crescimento de $20 \%$. O estudo destaca o crescimento de $54 \%$ na comercialização de notebooks e netbooks, chegando a 3 milhões de unidades no semestre. 
Assim, frente ao aumento da comercialização de novos produtos, considerase a geração de um grande volume de resíduos pela obsolescência dos equipamentos já usados. Frente a isso, vale a pena ter em mente os impactos ambientais que os REEE podem causar, em particular, pela composição destes. Segundo Widmer (2005), esses resíduos contêm mais de 1000 substâncias diferentes, muitas das quais são tóxicas, como por exemplo, chumbo, mercúrio, cádmio, arsênio, selênio, cromo hexavalente e retardantes de chamas que criam as emissões de dioxinas quando queimadas.

Tabela 1 - Indicadores de resíduos de equipamentos eletroeletrônicos.

\begin{tabular}{|c|c|}
\hline Tipo de indicador & Indicador \\
\hline Geração de resíduos eletroeletrônicos. & $\begin{array}{c}680.000 \\
\text { toneladas/ano }\end{array}$ \\
\hline $\begin{array}{l}\text { Projeção de geração média per capita anual de resíduos } \\
\text { eletroeletrônicos (2001 a 2030), considerando resíduos provenientes } \\
\text { de telefones celulares e fixos, televisores, computadores, rádios, } \\
\text { máquinas de lavar roupa, geladeira e freezers. } \\
\text { Projeção de geração média per capita anual de resíduos } \\
\text { eletroeletrônicos (2001 a 2030), considerando resíduos provenientes } \\
\text { de telefones celulares e fixos, televisores e computadores. }\end{array}$ & $3,4 \mathrm{Kg} /$ habitante \\
\hline $\begin{array}{l}\text { Projeção de acúmulo de resíduos eletroeletrônicos gerados entre } \\
2001 \text { e 2030, considerando resíduos provenientes de telefones } \\
\text { celulares e fixos, televisores, computadores, rádios, máquinas de } \\
\text { lavar roupa, geladeiras e freezers. }\end{array}$ & $\begin{array}{l}22 \text { milhões de } \\
\text { toneladas }\end{array}$ \\
\hline $\begin{array}{l}\text { Projeção de acúmulo de REEE gerados entre } 2001 \text { e } 2030 \text {, } \\
\text { considerando resíduos provenientes de telefones celulares e fixos, } \\
\text { televisores e computadores. }\end{array}$ & $\begin{array}{c}7 \text { milhões de } \\
\text { toneladas }\end{array}$ \\
\hline
\end{tabular}

Fonte: FEAM (2009).

O risco agregado ao descarte inadequado de REEE advém dos metais pesados que constituem as peças de um equipamento eletrônico e que são responsáveis pelos efeitos deletérios dos REEE. Vale destacar, ainda, que o descarte inadequado ou o aterramento e incineração sem tratamento prévio dos resíduos eletroeletrônicos resulta em contaminação da água, do solo ou do ar, devido à emissão de substâncias prejudiciais ao meio ambiente. A incineração, por sua vez, pode resultar na emissão de mercúrio, chumbo e outras substâncias tóxicas. Além de perda de material de alto valor econômico agregado, a exemplo do ouro e da prata, os quais são passíveis de reciclagem, bem como perda e incremento nos gastos de energia. (VIRGENS, 2009). 
Um aspecto que influencia o descarte de materiais eletrônicos refere-se à compra de novos equipamentos com o pretexto de aperfeiçoar a atividade do equipamento, gastando menos energia e resultando em um menor impacto ambiental. Para tanto, Kiatkittipong (2008) avaliou os padrões de uso de diversos produtos eletrônicos, entre eles monitores de computador do tipo tubo de raios catódicos (CRT) e de display de cristal líquido (LCD). Registrou-se que, embora o monitor do tipo LCD apresente um menor gasto no consumo de energia, desfazer-se do CRT existente e comprar um LCD novo pode não ser benéfico, pois a energia obtida pela diferença no consumo não é justificada. No caso de lâmpadas fluorescentes, recomendou-se sua utilização, devido ao baixo impacto ambiental de funcionamento, quando comparadas com as lâmpadas incandescentes.

Desta forma, uma boa alternativa voltada ao gerenciamento dos REEE consiste na Logística Reversa, a qual será discutida no tópico a seguir.

\subsection{LOGÍSTICA REVERSA}

Leite (2002) descreve a Logística Reversa como a área da Logística Empresarial que planeja, opera e controla o fluxo. Também, é responsável pelo domínio das informações logísticas correspondentes, do retorno dos bens de pósvenda e de pós-consumo ao ciclo de negócios ou ao ciclo produtivo, através dos Canais de Distribuição Reversos, agregando-Ihes valor de diversas naturezas: econômica, ecológica, legal, logística, de imagem corporativa, entre outras.

Segundo Gonçalves e Marins (2006), a logística reversa apresenta três vertentes que auxiliam o seu funcionamento: a) logística - o ciclo de vida de um produto não se encerra com a sua entrega ao cliente; b) financeira - existe o custo relacionado ao gerenciamento do fluxo reverso, que se soma aos custos já tradicionalmente considerados na Logística; c) ambiental - devem ser considerados e avaliados, os impactos do produto sobre o meio ambiente durante toda sua vida.

Dentro desses três conceitos, é possível notar que a ela visualiza o ciclo do produto desde a extração de matérias-primas até o destino final seguro, de modo que os aspectos financeiros acabam por englobar todo esse ciclo de vida, os custos 
associados e os impactos ambientais decorrentes, tornando impossível operar a logística reversa sem projetar essas três vertentes.

Sendo assim, a logística reversa é considerada um processo associado aos fluxos físicos inversos em toda a cadeia de suprimento materiais e fornecimentos de produtos acabados, de modo que inclui os que vão além da utilização pelo consumidor final, cujo ciclo é qualificado como fechado e os produtos recuperados, ou parte destes, reiniciam um novo ciclo de vida. (MOURA, 2006).

Na Figura 1, pode ser observada uma cadeia integrada de suprimentos cuja revitalização direta, recuperação de produtos e gestão de resíduos estão incluídas. Perceba-se que os produtos podem ser inseridos nos fluxos de logística reversa em qualquer fase do ciclo de vida, quando deixam de satisfazer os consumidores, permitindo assim que a utilidade do produto seja estendida através da reciclagem, remanufatura, renovação ou outras opções de valorização, entrando novamente no processo logístico direto. (THIERRY, 1995). A reutilização direta ou revenda representa os produtos de retorno que são oriundos de ajustes nos estoques de canais de distribuição direta. Normalmente, possuem condições gerais para serem reenviados ao mercado primário, ou seja, ao mercado original, com a marca do fabricante e através de redistribuição (CALDWELL, 1999).

Figura 1- Cadeia de suprimentos integrada

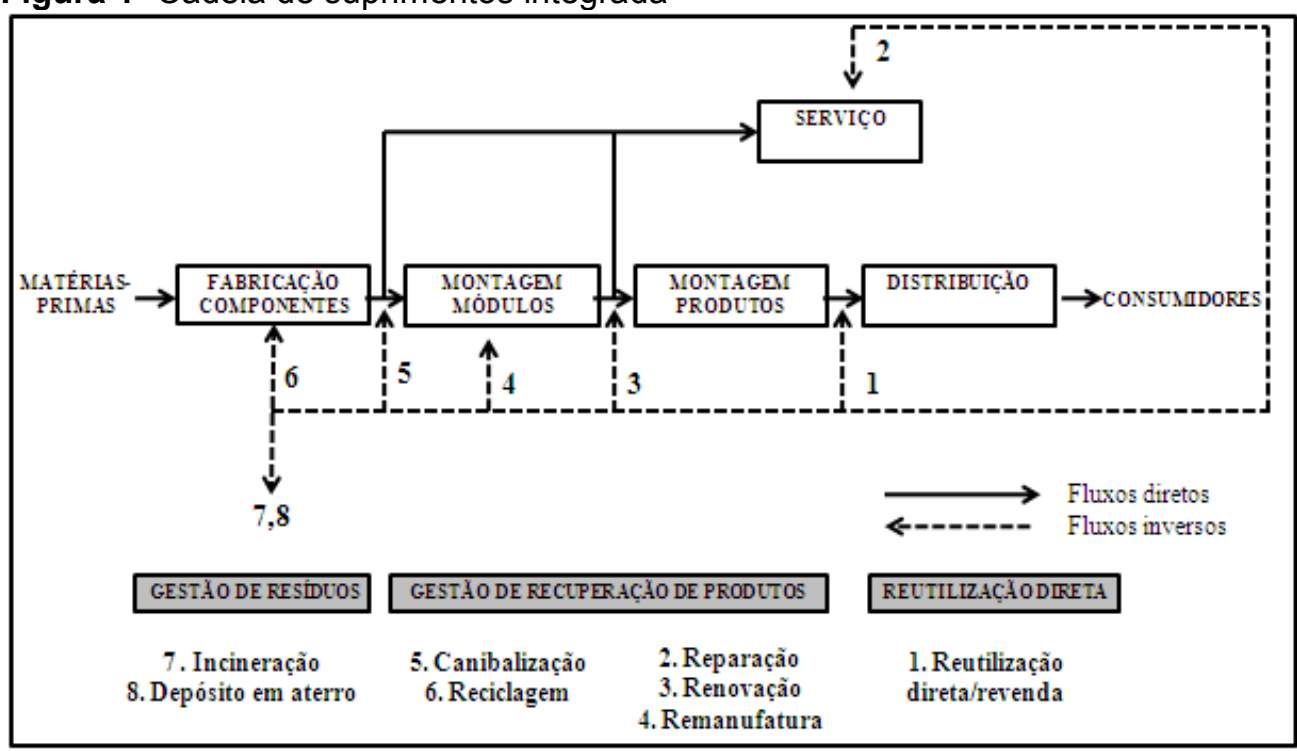

Fonte: Thierry (1995). 
Dentro dos processos de gestão de recuperação de produtos (Figura 1), podem-se encontrar os seguintes processos componentes do canal reverso, segundo Thierry (1995): i) reparo do produto: procedimento que envolve fixação e/ou substituição de peças quebradas e que, geralmente, requer apenas a desmontagem e a remontagem, podendo ser realizada nas instalações do cliente ou centros de assistência técnica do fabricante; ii) renovação: basicamente, o processo de atualização dos equipamentos combinado com as melhorias tecnológicas, fazendo a substituição de peças/módulos desatualizados; iii) remanufatura: processo industrial que consiste nas etapas de desmontagem do produto usado, na limpeza de suas peças, na reparação ou substituição de peças danificadas, atualização e remontagem do produto que deverá apresentar perfeitas condições de funcionamento, iguais a de um produto novo; iv) canibalização: apenas um conjunto limitado do produto está sendo reutilizado; estas peças podem ser utilizadas em reparação ou remanufatura; v) reciclagem: a identidade e a funcionalidade dos produtos e componentes são perdidas; o objetivo é a reutilização de materiais, a partir de produtos usados e seus componentes.

Dentro da gestão de resíduos têm-se, ainda, as opções de disposição final que devem ser consideradas em último caso, quando os resíduos remanescentes não são passíveis de recuperação. Não havendo nenhuma outra solução para agregar valor de qualquer natureza ao produto retornado ou de suas partes ou materiais, os mesmos são destinados a aterros sanitários ou ao processo de incineração, dependendo das peculiaridades de cada país ou região. (CALDWELL, 1999).

De modo geral, a logística reversa proporciona a revalorização dos produtos após o uso pelo consumidor, de modo que permita a reintrodução no fluxo de logística direta, possibilitando o retorno do produto atualizado, remanufaturado ou reciclado para o consumidor. Assim, a logística reversa apresenta importância fundamental na minimização de resíduos em aterros, visto que direciona os materiais reaproveitáveis de volta ao ciclo produtivo.

As diferentes alternativas e formas de comercialização podem, ainda, ser denominadas como canal de distribuição reverso, em que o processo de distribuição 
de retorno de produtos seja a finalidade principal, constituindo os canais de distribuição reversos de pós-consumo e pós-venda.

\subsection{LEGISLAÇÃO AMBIENTAL COMO FATOR INDUTOR DA LOGÍSTICA REVERSA DE REEE}

A Política Nacional de Resíduos Sólidos vinha sendo discutida há 19 anos no Brasil. Em agosto de 2010, finalmente, foi sancionada a Lei 12305/2010. Sua política traça diretrizes aplicáveis aos resíduos sólidos, destacando não só a responsabilidade dos geradores e do poder público, bem como a responsabilidade compartilhada, a qual abrange fabricantes, importadores, distribuidores, comerciantes, consumidores e titulares dos serviços públicos de limpeza urbana e de manejo de resíduos sólidos.

Quanto aos REEE, segundo a PNRS, a responsabilidade do usuário final é limitada à devolução do resíduo. Dessa forma, na implantação dos sistemas de logística reversa pelo fabricante ou importador, com sistema obrigatório de coleta e retorno de produtos ou REEE, os distribuidores e os pontos de venda serão obrigados a recebê-los em depósito.

Os principais aspectos da lei se resumem em logística reversa, gestão integrada de resíduos sólidos e um inventário da geração de resíduos sólidos. Esses três pontos em conjunto são fundamentais para o sucesso da lei no país e destinamse a satisfazer a ausência de políticas ambientais no Brasil. Destaca-se, portanto, a logística reversa como uma ferramenta de planejamento e controle dos REEE, proporcionando vantagens mútuas para a indústria, importadores e varejistas, ao passo em que aumenta o poder de competição das empresas e melhora seu relacionamento com fornecedores e clientes.

Porém, mesmo depois de tantos anos em discussão, a proposta final é marcada pela ausência de metas e prazos para implementar as medidas impostas, dificultando a avaliação de sua eficiência na gestão dos resíduos sólidos. Ainda assim, a lei representa um avanço para a área de resíduos sólidos do país, visto que 
desperta a discussão do assunto e permite uma abertura para possíveis mudanças na mentalidade de consumidores e produtores.

Para tanto, a PNRS traz a definição de responsabilidades em direção ao desenvolvimento sustentável, de modo que Estados e municípios se vêem obrigados a elaborar planos de resíduos sólidos, seguindo as bases da PNRS e antecipandose em uma perspectiva de vinte anos, com revisões de quatro em quatro anos. Quanto ao varejo, a lei apresenta a necessidade de se adaptarem à nova conduta empresarial, visto que passarão a servir de conexão entre clientes e indústrias, através dos postos de coleta de resíduos eletrônicos.

O Brasil apresenta, outrossim, algumas resoluções em vigor, como por exemplo, a Resolução CONAMA n 401/08, que determinou a nova redução nos limites de mercúrio, cádmio e chumbo permitidos na composição das pilhas e baterias (BRASIL, 2008); a Resolução CONAMA n² 23/96 que definiu o que são resíduos perigosos e não perigosos, assim como destacou as diretrizes para os movimentos transfronteiriços de resíduos perigosos e o seu depósito. (BRASIL, 1996).

De modo geral, é possível observar que os aspectos legais referentes aos mais diversos resíduos resumem-se a orientar o fluxo por canais reversos e a manifestar onde a disposição dos resíduos não deve ocorrer. Todavia, as resoluções e leis não indicam como deve ocorrer a disposição final, deixando uma lacuna a ser preenchida por fabricantes e governos.

Fora do Brasil, é possível identificar algumas iniciativas no setor dos resíduos eletrônicos, como é o caso da Comunidade Europeia que dispõe da Diretiva 2002/96/CE, que trata dos Resíduos de Equipamentos Elétricos e Eletrônicos (WEEE ou REEE) e a Diretiva 2002/95/CE sobre a Restrição do Uso de Substâncias Perigosas (RoHS). A WEEE está em vigor desde 2006, com a finalidade prevenir a geração de resíduos de equipamentos elétricos e eletrônicos, utilizando-se de práticas de reutilização, reciclagem e outras formas de valorização dos resíduos. (UNIÃO EUROPEIA, 2003a; UNIÃO EUROPEIA 2003b).

O ponto chave e diferencial da directiva WEEE é o príncipio de Responsabilidade Ampliada do Produtor. Segundo Ji (2011), a directiva repousa no argumento de que os impactos ambientais são substancialmente determinados no

Revista Produção Online, Florianópolis, SC, v.13, n. 2, p. 544-576, abr./jun. 2013. 
ponto de projeto, onde é realizada a escolha dos materiais, processos e tecnologias de acabamento, ou seja, com o fabricante. Assim, o fabricante tem a responsabilidade de produzir equipamentos que possibilitem uma reparação ou remanufatura, extendendo a vida útil, além de assumir a responsabilidade sobre o destino final destes resíduos. Indiretamente, o propósito é fomentar políticas que incentivem as empresas a selecionar as matérias-primas empregadas em seus produtos, conforme a capacidade de causar um menor impacto ao meio ambiente, ao passo em que estimula a geração de mecanismos tecnológicos que modificam os modelos produtivos existentes.

A Diretiva RoHS, por sua vez, tem por objetivo aproximar as legislações dos Estados-Membros em matéria de restrições ao uso de substâncias perigosas em equipamentos elétricos e eletrônicos, contribuindo para a proteção da saúde humana e para uma valorização e eliminação, em boas condições ambientais, dos resíduos de equipamentos elétricos e eletrônicos. A diretiva assegura que os novos equipamentos colocados no mercado não contenham chumbo, mercúrio, cádmio, cromo hexavalente, polibromobifenilo (PBB) e/ou éter de difenilo polibromado (PBDE).

A diretiva imposta pela Comunidade Europeia teve grande impacto no mercado global, de modo que outros países têm buscado se adaptar às novas medidas, para continuar exportando produtos ou componentes para os países da União Europeia, ao mesmo tempo em que atendem às novas necessidades em termos de substâncias perigosas e responsabilidade por coleta e reciclagem. Assim, a diretiva europeia não é apenas uma medida restrita aos países membros, mas sim uma medida de impacto global que tem incentivado países desenvolvidos e subdesenvolvidos a gerenciar seus resíduos eletrônicos e respeitar o uso racional de recursos naturais.

\section{PROCEDIMENTOS METODOLÓGICOS}

\subsection{DESCRIÇÃO DA DEFINIÇÃO DA AMOSTRAGEM}


Para o objeto de estudo foi estabelecida uma população-alvo que se concentra nas empresas do comércio varejista e assistência técnica da cidade de Natal/RN. Assim, foi possível identificar um universo de 30 empresas, devidamente cadastradas e em pleno funcionamento, abrangendo os serviços de comércio varejista (14 empresas) e assistência técnica (16 empresas). Entre as 30 empresas encontradas, foi possível identificar que: 11 pertenciam à ANEINFO - Associação Norte-Riograndense das Empresas de Informática do RN (Tabela 2); no total, apenas 20 empresas aceitaram responder o questionário estruturado (10 empresas de comércio varejista e 10 de assistência técnica).

A escolha pelo comércio varejista e de assistência técnica justifica-se pelo relevante papel dessas empresas na promoção da sustentabilidade empresarial, visto que esses setores atuam diretamente com o consumidor, podendo combater os impactos do circuito produção-consumo que acarretam prejuízos ecológicos (MACEDO, 2007). Assim, a possibilidade de atuar junto ao cliente, através da conscientização ambiental e do incentivo à sustentabilidade empresarial, serve de alicerce para encontrar o equilíbrio entre as relações consumidor-empresa, permitindo novas possibilidades ao cliente que busca por tecnologia aliada ao consumo consciente. Além disso, em especial, o varejo está localizado na cadeia de valor entre a produção e o consumo, podendo atuar nessas duas direções, adotando critérios de compra que ampliem o tradicional binômio preço-qualidade, podendo induzir seus fornecedores a equacionar problemas sociais e ambientais na produção ou extração dos produtos. (CARDOSO, 2008).

Tabela 1 - Número de empresas encontradas, entrevistadas e percentual das empresas entrevistadas

\begin{tabular}{|c|c|c|c|c|c|c|c|}
\hline \multirow[b]{2}{*}{ Empresas } & \multicolumn{3}{|c|}{ Varejo } & \multicolumn{4}{|c|}{ Assistência técnica } \\
\hline & $\begin{array}{l}\text { Encon- } \\
\text { Tradas }\end{array}$ & $\begin{array}{l}\text { Entrevis- } \\
\text { Tadas }\end{array}$ & & $\begin{array}{l}\text { Encon- } \\
\text { Tradas }\end{array}$ & $\begin{array}{c}\text { Entrevis- } \\
\text { Tadas }\end{array}$ & & $\%$ \\
\hline Aneinfo & 9 & 7 & 7,7 & 2 & 2 & 00 & 1 \\
\hline $\begin{array}{l}\text { Não } \\
\text { associadas }\end{array}$ & 5 & 3 & 0 & 4 & 8 & 7,1 & 5 \\
\hline Total & 1 & 10 & & 6 & 10 & & - \\
\hline
\end{tabular}

O método utilizado para coleta de dados ocorreu através de visitas a cada uma das empresas, no período de julho a setembro de 2010, por meio de uma 
entrevista pessoal, nas quais as informações foram solicitadas e colhidas junto ao responsável de cada empresa, através da aplicação do questionário estruturado, sendo que algumas empresas optaram por enviar as respostas via correio eletrônico.

\subsection{INSTRUMENTO DE COLETA DE DADOS}

O procedimento utilizado para a realização da coleta de dados sustentou-se na definição e uso de um questionário contendo perguntas com graus de opinião (14), de acordo com a escala do tipo Likert, cuja qualificação das respostas possíveis se organizavam em grupos para cada questionamento aplicado. A opção de se utilizar a escala Likert deu-se pela vantagem desse procedimento levar a uma variabilidade, mensurando o posicionamento do entrevistado (SILVA, 2009).

Foram utilizadas um total de 23 variáveis analíticas, divididas em 4 grupos, sendo eles: (i) Nível de Consciência sobre os Resíduos de Equipamentos Eletroeletrônicos; (ii) Práticas de Gestão Ambientais; (iii) Gestão de Resíduos de Equipamentos Eletroeletrônicos; (iv) Caracterização das Empresas e Respondentes.

No grupo Nível de Consciência sobre os Resíduos de Equipamentos Eletroeletrônicos (NCO), os questionamentos tinham por objetivo avaliar a percepção ambiental dos respondentes frente à responsabilidade da disposição final dos REEE pelas empresas de TI; investigar a importância de práticas preventivas de gerenciamento de REEE, por exemplo, a reciclagem; constatar a priorização de fabricantes que adotam práticas ambientais de pós-consumo.

Desta forma, o grupo NCO foi composto por um total de 5 variáveis analíticas, sendo elas: NCO_RRE (Nível de consciência sobre a responsabilidade pelo recolhimento e tratamento dos resíduos eletrônicos); NCO_GRE (Nível de consciência que as empresas atribuem à importância dada pelos clientes ao gerenciamento dos resíduos eletrônicos); NCO_INC (Importância de incentivar o uso de equipamento até o fim de sua vida útil); NCO_REC (Importância de realizar a reciclagem dos resíduos eletrônicos) e NCO_FAB (Importância de se priorizar os fabricantes que possuem uma política de incentivo de retorno de produtos pósconsumo). Como escala de resposta, neste grupo, foi utilizada a escala Likert, sendo 
as opções: sem importância (1), pouco importante (2), importante (3) e muito importante (4). Também era possível a opção, sem opinião, a qual não havia uma pontuação.

O segundo grupo de variáveis intitulado Práticas de Gestão Ambientais (PAD) buscou analisar a frequência do desenvolvimento de algumas práticas preventivas relacionada ao gerenciamento de REEE. Nesse sentido, as variáveis componentes deste grupo foram: PAD_FAB (Frequência em que prioriza fabricantes com política de retorno pós-consumo); PAD_EDA (Frequência da realização de ações voltadas para educação ambiental com os funcionários, informando sobre as questões ambientais dentro da atividade da empresa e alertando sobre os riscos dos REEE e necessidade de reciclagem); PAD_CLI (Frequência de implementação de campanhas de conscientização ambiental junto aos clientes relacionadas ao recolhimento dos resíduos eletrônicos) e PAD_RNR (Frequência da aplicação de regulamentos, normas ou regras no gerenciamento de resíduos eletrônicos). Como escala de resposta, adotaram-se as seguintes opções: Nunca (1), Quase nunca (2), Algumas vezes (3) e Sempre (4), Sem opinião (-).

Já o grupo Gestão de Resíduos de Equipamentos Eletroeletrônicos (GES) teve por objetivo analisar o nível de maturidade do gerenciamento de REEE, através da existência de um Plano de Gerenciamento de Resíduos - PGRS; a existência de uma área de armazenamento temporário de resíduos, além de práticas de reciclagem interna e análise da destinação e disposição final dos REEE gerados pelas empresas. Esse grupo contou com 4 variáveis, sendo elas: GES_PGI (Existência de um PGRS); GES_RIE (Existência de reciclagem interna dos REEE, de forma a promover o reaproveitamento de algum tipo de material dentro da própria empresa); GES_AAR (Existência de uma específica de armazenamento de REEE) e GES_DFI (Destino e disposição final dos REEE recebidos e/ou gerados pela empresas estudadas). A escala de resposta adotada neste grupo, com exceção de GES_DFI, foi: Não implementado (1), em implementação (2), implementado (3) e implementado e em manutenção (3), sem opinião (-). Para a variável GES_DFI, as opções foram: Lixão, Aterro, Doação a terceiros, Reciclagem, Catadores, Tratamento e outros. 
Enfatiza-se que as variáveis dos grupos PAD e GES foram estabelecidas em consonância com a PNRS (BRASIL, 2010), de forma a atender os objetivos desta pesquisa.

A figura 2 apresenta o escopo da aplicação das variáveis dos grupos NCO, PAD e GES, em relação à cadeia Fabricante x Empresas de Comercialização, Assistência Técnica e os Clientes.

Por fim, para a caracterização das empresas e dos respondentes em um grupo de 4 variáveis analíticas, foi analisado o porte das empresas, o faturamento anual, o tempo de atuação no mercado, a existência da licença ambiental e a adoção de um SGA e o Programa de Produção mais Limpa. Também, buscou-se definir o perfil dos respondentes, sendo analisado o sexo, a faixa etária, o grau de instrução e o tempo médio na empresa.

Figura 2 - Variáveis dos Grupos NCO, PAD e GES e seu limite de aplicação

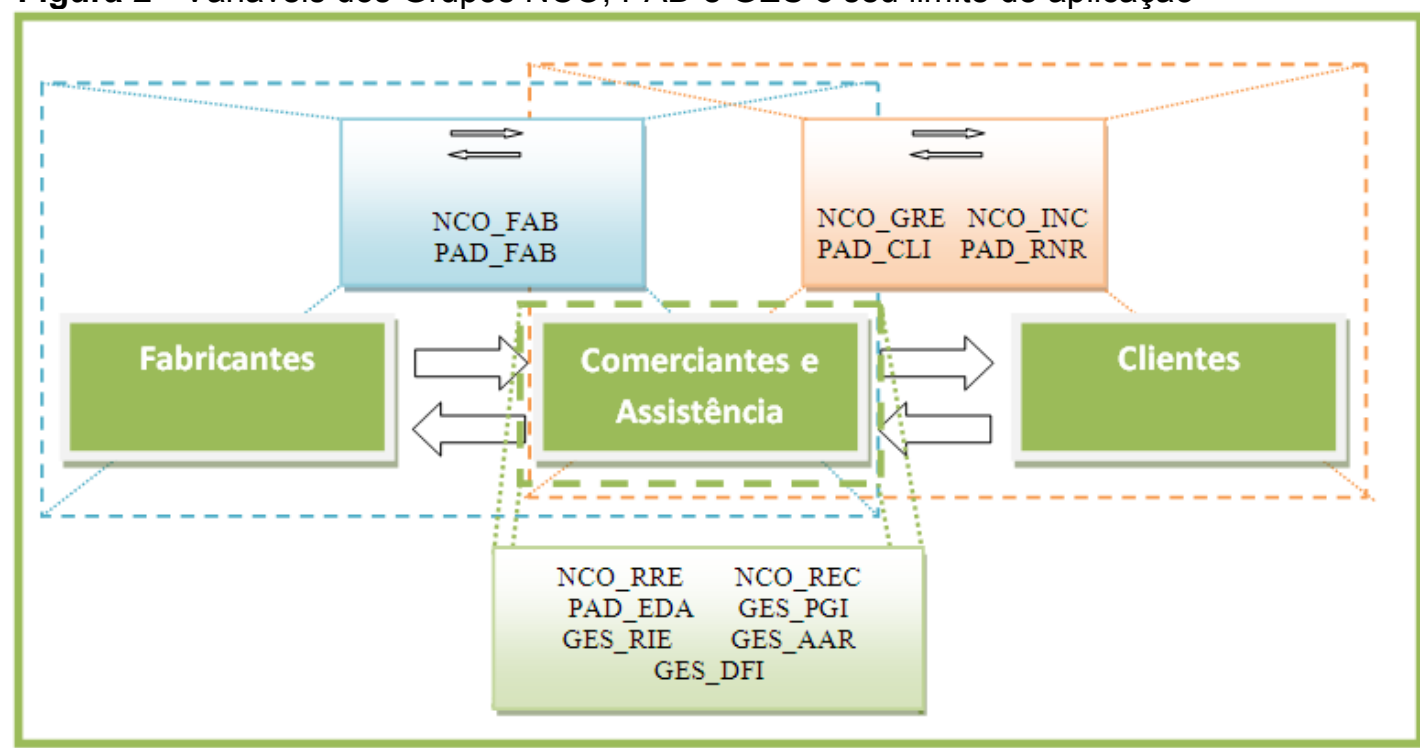

\section{RESULTADOS E DISCUSSÕES}

\subsection{CARACTERIZAÇÃO DAS EMPRESAS E DOS RESPONDENTES}

Em relação ao porte das empresas amostradas, constatou-se que $75 \%$ correspondiam à micro empresas com até 19 funcionários; $15 \%$ eram de pequeno 
porte, contendo entre 20 e 99 funcionários; $5 \%$ eram empresas de médio porte, contendo entre 100 e 499 funcionários.

O tempo de atuação no mercado das empresas variou de 1 ano e meio a 23 anos, de modo que, aproximadamente, $40 \%$ da amostra se concentrou em até 8,7 anos de atuação no mercado, enquanto $20 \%$ apresentou uma atuação no mercado superior a 19,5 anos.

No que tange ao faturamento anual, foi observada uma variação significativa e tal informação não foi fornecida por todas as empresas. O faturamento mínimo informado corresponde a 36.000 reais e o faturamento máximo informado corresponde a 90.000.000 reais. De forma geral, a amostra apresentou uma concentração de $40 \%$ com faturamento entre 36.000 e 400.000 reais, $5 \%$ com 22.000 .000 reais e $5 \%$ com 90.000 .000 reais.

Em termos de práticas ambientais, as empresas foram questionadas sobre licença ambiental, certificação SGA ISO 14001 e produção mais limpa (PAD_PML). Em relação à existência de licença ambiental, 40\% das empresas afirmaram possuir, $40 \%$ disseram que não têm e $20 \%$ desconheciam a prática. Tem-se, ainda, que $95 \%$ das empresas não possuíam certificação SGA 14001, sendo que 5\% desconheciam a prática; 35\% possuíam medidas de produção mais limpa, $45 \%$ não tinham e $20 \%$ desconheciam a prática.

Em relação aos respondentes, havia uma predominância do sexo masculino, representando $90 \%$ da amostra, enquanto as mulheres representaram 5\%. No que tange à faixa etária, $50 \%$ dos respondentes tinham mais de 35 anos; $35 \%$ estão entre 25 e 35 anos; apenas 10\% se encontravam com idade entre 19 e 25 anos. Finalmente, de um modo geral, $5 \%$ representam as informações omitidas durante o questionário.

No que diz respeito ao grau de instrução, destaca-se o fato de a maioria dos respondentes possuírem ensino superior (55\%), sendo que $20 \%$ tinham ensino superior incompleto e apenas 5\% tinham ensino médio incompleto. Dentre os respondentes, $70 \%$ eram casados, $15 \%$ solteiros e $10 \%$ divorciados. Em relação ao número de filhos, $70 \%$ tinham filhos. 
O tempo médio de empresa dos respondentes variou de 1 ano e 4 meses até 21 anos, de modo que apresentou uma concentração de 55\% da amostra com até 7,9 anos de empresa. Apenas 20\% apresentaram mais de 14,5 anos de empresa.

\subsection{NÍVEL DE CONSCIÊNCIA SOBRE OS REEE}

Neste agrupamento, inicialmente foi analisado o nível de consciência sobre a responsabilidade pelo recolhimento e tratamento dos resíduos eletrônicos (NCO_RRE) (Figura 3). Pelos resultados, observou-se que 5\% da amostra considerou que o Governo era o principal responsável pelo recolhimento e tratamento dos resíduos eletrônicos; $15 \%$ atribuíram ao fabricante essa responsabilidade; $20 \%$ ao Governo e ao fabricante. Apenas 35\% apresentaram uma visão compartilhada da responsabilidade. Esse resultado apresentou-se bastante disperso, revelando que as empresas ainda não tinham uma posição definida no que diz respeito ao responsável pelo recolhimento e tratamento de seus próprios resíduos. No entanto, é possível observar que $60 \%$ das empresas se incluíram no grupo responsável pelo tratamento, com $40 \%$ da amostra responsabilizando o governo e/ou fabricante.

No que concerne à PNRS, a responsabilidade pelo produto pós-consumo deve ser compartilhada por todos os integrantes da cadeia produtiva, por meio da aplicação da logística reversa. Um exemplo interessante é o da Suíça. Considerada um mercado consumidor maduro para produtos elétricos e eletrônicos, ela adota o princípio da responsabilidade estendida do produtor (EPR), reunindo membros da indústria para assumir suas responsabilidades por todos os impactos dos produtos. Esse modelo, introduzido mesmo antes da legislação, levou a Suíça a ser pioneira em legislar e gerenciar esse tipo de resíduo. (KHETRIWAL, 2009). 
Figura 3 - Representação gráfica com as percentagens de responsabilidade pelo recolhimento e tratamento dos resíduos eletrônicos (NCO_RRE)

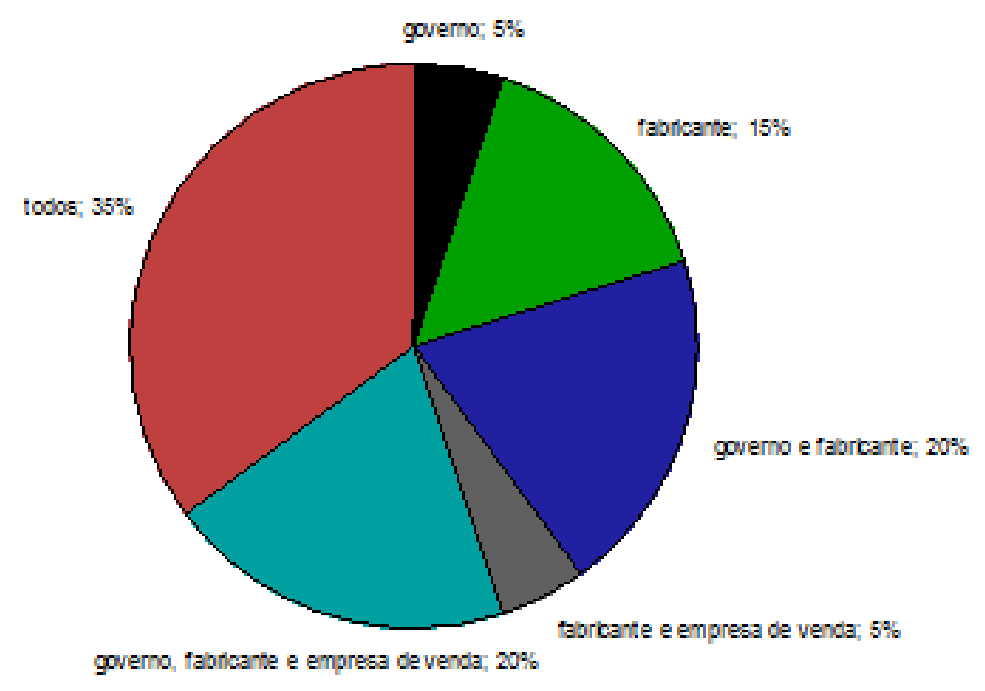

Já em relação ao nível de consciência que as empresas atribuem à importância dada pelos clientes ao gerenciamento dos resíduos eletrônicos (NCO_GRE), foi constatado que $5 \%$ das empresas investigadas acreditavam que o cliente atribui muita importância ao gerenciamento dos REEE, da seguinte forma: $25 \%$ importante, $40 \%$ pouca importância e $25 \%$ sem importância. Entre os $30 \%$ de empresas que julgaram importante ou muito importante para a variável NCO_GRE, destaca-se que: $66,7 \%$ eram micro empresas; $16,7 \%$ pequenas empresas. As empresas possuíam faturamento anual que variava de trinta e seis mil reais a noventa milhões; $33,3 \%$ tinham licença ambiental, $50 \%$ não tinham licença ambiental.

Um fator inibidor para o desenvolvimento de ações de gerenciamento de resíduos pode ser constatado na postura daquelas empresas que não consideraram importante $o$ desenvolvimento de ações com os clientes, no tocante a esse gerenciamento. Ou seja, nesta amostragem, a pressão movida pelos clientes para adoção de uma postura ambiental adequada pelas empresas (DONAIRE, 1999; BARBIERI, 2004) não é considerada tão representativa. 
A variável NCO_INC (Importância de incentivar o uso de equipamento até o fim de sua vida útil) revelou que $10 \%$ da amostra não atribuiu importância ao procedimento de incentivar os clientes a aproveitar seus equipamentos eletrônicos até o fim de sua vida útil; $5 \%$ atribuiu pouca importância; $45 \%$ considera importante e $40 \%$ muito importante. No total, $85 \%$ variaram de importante a muito importante, sendo representado por $76,5 \%$ de micro empresas, $17,6 \%$ de pequenas empresas; com faturamento anual variando de trinta e seis mil reais a noventa milhões de reais; $41,2 \%$ têm licença ambiental.

É importante observar que a extensão de vida útil dos equipamentos proporciona uma diminuição no fluxo de resíduos dispostos inadequadamente em aterros, ao passo em que com a logística reversa tem uma perspectiva de redução na fonte, reciclagem, substituição de materiais, reuso de materiais, reparação, etc., tornando possível tanto o desagravo dos impactos ambientais causados por produtos elétricos e eletrônicos, quanto o ganho de eficiência e sustentabilidade das operações nas organizações (STOCK; LAMBERT, 1992). Assim, medidas como upgrade (atualização para versão mais recente) e reparos podem estender a vida útil de um equipamento, sem interferir na qualidade do mesmo. Apesar de a extensão de vida útil de um produto eletrônico representar, em alguns casos, um maior consumo de energia, visto que aparelhos eletrônicos consomem mais energia do que os aparelhos novos, este processo é recompensado pela redução de consumo de energia para fabricação de novos produtos. (TRUTTMANN; RECHBERGER, 2006).

Em relação à variável NCO_REC (Importância de realizar reciclagem dos resíduos eletrônicos) foi observado entre as empresas que $60 \%$ atribuíam muita importância à realização de reciclagem dos resíduos eletrônicos recolhidos; $30 \%$ consideraram importante; $10 \%$ pouco importante. No total, $90 \%$ das empresas variaram de importante a muito importante, destacando que elas possuíam consciência dos impactos ambientais causados por resíduos eletrônicos, reconhecendo a necessidade de reciclagem.

A importância de as empresas estabelecerem canais reversos de reciclagem, servindo de elo entre consumidor e fabricante, acentua-se quando se verifica que não são todos os clientes que estão dispostos a pagar pela reciclagem. Nesse 
aspecto, Chung (2011) realizou uma pesquisa em Hong Kong, abordando aspectos da geração e medidas de controle para lixo eletrônico a qual revelou que $28,4 \%$ dos entrevistados não estariam dispostos a pagar pelo descarte adequado dos resíduos (Televisão, máquina de lavar, ar-condicionado, geladeira e computador). Logo, além de os fabricantes e as empresas assumirem a responsabilidade pelo tratamento dos resíduos eletrônicos, os consumidores rejeitaram a ideia de pagar pelo descarte adequado, visto que consideram que esta seja uma responsabilidade do fabricante.

A variável NCO_FAB trata da importância de se priorizar fabricantes que possuem uma política de incentivo de retorno de produtos pós-consumo, de modo que $5 \%$ consideraram pouco importante, 30\% importante e $65 \%$ muito importante. No total, $95 \%$ da amostra variou de importante a muito importante.

\subsection{PRÁTICAS DE GESTÃO AMBIENTAL}

A variável PAD_FAB (Frequência em que prioriza fabricantes com política de retorno pós-consumo) revelou que $10 \%$ não manifestaram opinião; $40 \%$ nunca priorizaram fabricantes com política de incentivo de retorno de produto pósconsumo; $20 \%$ quase nunca priorizam; $5 \%$, algumas vezes; $25 \%$, sempre. Esse resultado contrasta com os dados da variável NCO_FAB (Importância de priorizar fabricantes com política de retorno pós-consumo) que apresentou 95\% da amostra, variando de importante a muito importante.

Correlacionando as informações acima a um diagrama de dispersão (Figura 4), tendo no eixo das abscissas NCO_FAB e no eixo das ordenadas PAD_FAB, foi confirmada a correlação negativa de valor $-0,2776$, de modo que não existe correlação entre as respostas das duas variáveis, visto que os respondentes não mantiveram o comportamento esperado. Em outras palavras, apesar de considerar importante a priorização de fabricantes com política de retorno pós-consumo, as empresas não a efetuam na sua maioria tal prática.

Um exemplo de fabricante que recebe seus resíduos eletrônicos pósconsumo é apresentado por Kerr e Ryan (2001) que estudaram o caso da empresa Xerox, nos Estados Unidos, a qual utiliza a logística reversa em seus processos, 
realizando a desmontagem dos produtos, a seleção de destino e a reutilização. $\mathrm{O}$ caso Xerox promove a revalorização logística dos equipamentos usados, ao passo em que promove a revalorização econômica, tecnológica e ecológica, além de propiciar agregação de valor e competitividade diferenciada.

A variável PAD_EDA trata da realização de ações voltadas para educação ambiental com os funcionários, informando sobre as questões ambientais dentro da atividade da empresa e alertando sobre os riscos dos REEE e necessidade de reciclagem. Ocorre que $40 \%$ das empresas afirmaram não apresentar nenhum tipo de atividade de educação ambiental implementada; 25\% disseram estar em processo de implementação; 30\%, implementadas; e 5\% asseguram estar implementadas e em manutenção.

Mesmo nas empresas que disseram realizar ações de educação ambiental, observa-se que esta ocorria através de medidas tímidas, utilizando cartazes; já outras empresas (minoria) afirmaram realizar treinamentos de poucos meses com novos funcionários. Segundo Cloquell-Ballester (2008), as pequenas e médias empresas não estão isentas de contaminação ambiental, representando uma escassez de formação ambiental entre seus funcionários. No entanto, estas empresas já têm mostrado níveis de entusiasmo para promover a educação ambiental de seus funcionários, possibilitando a correção de erros operacionais que podem gerar resíduos e acidentes ambientais. 
Figura 4 - Diagrama de dispersão correlacionando as variáveis $P A D \_F A B$ (freqüência em que prioriza fabricantes com política de incentivo de retorno) e NCO_FAB (importância de priorizar fabricantes com política de incentivo de retorno).

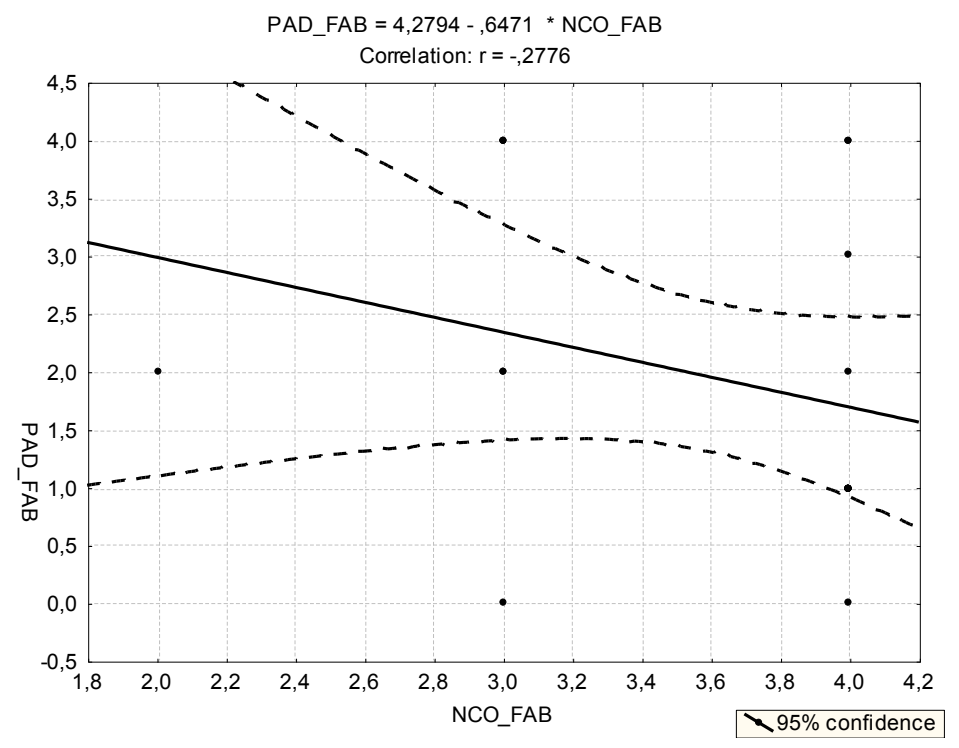

A variável PAD_CLI apresenta o aspecto da implementação de campanhas de conscientização ambiental, junto aos clientes, as quais estão relacionadas ao recolhimento dos resíduos eletrônicos. Dentre as empresas, 5\% não manifestaram opinião, 65\% afirmaram não apresentar a medida implementada, 25\% asseguraram que estavam em implementação e apenas 5\% foram implementadas (Microempresa, faturamento anual de cento e cinquenta mil reais, não tem licença ambiental e SGA). O alto percentual de empresas que afirmaram não executar a medida, refere-se ao fato de que a maioria não adotara procedimentos adequados para tratar e dispor os resíduos e, por vezes, não recebia resíduos de consumidores, por isso não havia campanhas de conscientização ambiental com os clientes. Acredita-se que esse baixo desempenho, referente ao desenvolvimento de ações de educação ambiental com os clientes, seja reflexo do que as organizações julgam como verdade: que os clientes não dão importância à temática do gerenciamento de REEE.

A variável PAD_RNR trata da aplicação de regulamentos, normas ou regras no gerenciamento de resíduos eletrônicos. Pelos resultados, foi constatado que $70 \%$ das empresas não aplicavam nenhum tipo de regulamento, 20\% estavam em 
processo de implementação e apenas 10\% afirmaram utilizar algum tipo de regulamento no gerenciamento de seus resíduos eletrônicos (Uma das empresas afirmou utilizar o manual do fabricante como orientação no gerenciamento dos resíduos). Esse resultado é consequência da ausência de políticas formais direcionadas aos resíduos eletrônicos, levando cada empresa a gerenciar os resíduos de forma independente e sem seguir normas de coleta, armazenamento, tratamento e disposição final. Fato que repercute nas grandes cidades brasileiras e dificulta o descarte adequado dos resíduos. É possível observar, também, que pouquíssimas empresas citam a PNRS e suas novas medidas para os resíduos eletrônicos, inferindo-se que não há conhecimento ou interesse.

\subsection{GESTÃO DOS RESÍDUOS DE EQUIPAMENTOS ELETROELETRÔNICOS (GES)}

De acordo com a PNRS, um Plano de Gerenciamento de Resíduos Sólidos (PGRS) deve conter, no mínimo, descrição do empreendimento ou atividade; diagnóstico dos resíduos sólidos gerados ou administrados, contendo a origem, o volume e a caracterização dos resíduos, incluindo os passivos ambientais a eles relacionados; identificação das soluções consorciadas ou compartilhadas com outros geradores; ações preventivas e corretivas a serem executadas em situações de gerenciamento incorreto ou acidentes; metas e procedimentos relacionados à minimização da geração de resíduos sólidos, à reutilização e reciclagem; e, se couber, ações relativas à responsabilidade compartilhada pelo ciclo de vida dos produtos.

A variável GES_PGI buscou averiguar a implementação de um PGRS pelas empresas geradoras de REEE na amostragem analisada. Pelos resultados, foi constatado que 35\% não apresentavam o PGRS implementado, $20 \%$ estavam em processo de implementação, 35\% apresentavam o plano implementado e apenas $5 \%$ continham o PGRE implementado e em manutenção. No total, $40 \%$ das empresas apresentavam o PGRE implementado. Destas, a maioria afirmou ter um plano de gerenciamento e assumiu que o plano funcionava de mdo informal, por 
vezes estimulado pela obtenção de um selo de qualidade, nem sempre atendendo aos requisitos básicos. Vale destacar que nenhuma das empresas apresentou 0 plano documentado no momento da aplicação do questionário.

Entre as empresas que apresentavam o PGRS implementado (35\%) ou implementado e mantido (5\%), pode-se constatar que tinham um perfil de $62,5 \%$ de micro empresas, $25 \%$ pequenas empresas; com um faturamento anual variando de quatrocentos mil reais a noventa milhões de reais. $62,5 \%$ das empresas possuíam a licença ambiental e $62,5 \%$ das empresas tinham implementadas as ações de educação ambiental com os funcionários.

Detalhando os elementos do plano de gerenciamento, a variável GES_RIE buscou avaliar a existência de reciclagem interna dos REEE, de forma a promover o reaproveitamento de algum tipo de material dentro da própria empresa. Dentre as empresas, $5 \%$ não manifestaram opinião, 35\% não apresentavam a medida implementada, 20\% estavam em implementação, 30\% tinham a medida implementada e apenas $10 \%$ tinham a medida implementada e em manutenção.

Em comparação com o resultado apresentado pela variável NCO_REC (Importância de realizar reciclagem dos resíduos eletrônicos), pode-se perceber que 90\% da amostra considerou importante ou muito importante a reciclagem de resíduos eletrônicos armazenados e/ou recolhidos na empresa, mas apenas 40\% apresentavam a medida de reciclagem interna implementada ou implementada e em manutenção.

Práticas de reaproveitamento de peças e equipamentos dentro da própria empresa são mais comumente observadas nas empresas de manutenção, visto a própria necessidade do serviço que manipula peças de eletrônicos.

Analisando criticamente 0 modelo de gerenciamento de resíduos implementado, buscou-se, inicialmente, cruzar as seguintes variáveis: nível de maturidade do plano de gerenciamento de resíduos eletrônicos (GES_PGI) e a existência de reciclagem interna dos resíduos eletrônicos (GES_RIE). Pelos resultados, foi observado que, das empresas que possuíam plano de gerenciamento implementado, um total de 8 empresas, 5 delas possuíam a prática de reciclagem interna. Com relação às empresas que estavam em processo de implementação (4 
empresas), seus planos de gerenciamento, em três delas, apresentavam medidas de reciclagem interna.

A reciclagem interna apresenta um aspecto interessante dentro do contexto da logística reversa, visto que proporciona uma redução de resíduos no ponto de geração, atendendo, ainda, a uma das exigências feitas pela PNRS que indica a redução, a reutilização e a reciclagem como medidas atreladas ao gerenciamento de resíduos eletrônicos.

Por fim, foi analisada a existência de uma área específica de armazenamento temporário dos REEE nas empresas estudadas (Variável GES_AAR), considerando a importância de se manter a qualidade dos materiais a receberem a destinação ambientalmente adequada. Pelos resultados, foi observado que $10 \%$ preferiram não manifestar opinião, 35\% disseram não haver nada implementado, 25\% afirmaram estar em implementação e 30\% implementados. Destes 30\% que afirmaram ter uma área específica para armazenamento de resíduos, 66,6\% armazenavam em caixas de papelão e 33,3\% em tambor em área coberta.

Apesar de não haver regulamento específico para o armazenamento de resíduos sólidos especiais (pneumáticos, pilhas e baterias, equipamentos e componentes eletrônicos, entre outros), é sensato observar as medidas gerais impostas pelas normas da ABNT - NBR 11174/1990 e NBR 12235/1992, que tratam respectivamente de armazenamento de resíduos não perigosos e armazenamento de resíduos perigosos.

Ainda, analisando criticamente o PGRS adotado pelas empresas, buscou-se relacionar com a implantação destes nas empresas, a existência de uma área de armazenamento para os REEE. Assim, foi constatado que, das empresas que tinham o plano implementado (um total de 8 empresas), 5 empresas possuíam área de armazenamento e 2 estavam em implantação. Destaca-se, também, uma empresa que não possuía um plano de gerenciamento de resíduos eletrônicos, mas que afirmava possuir uma área específica para armazenar esse tipo de resíduo.

Por fim, a variável GES_DFI abordou o destino e disposição final dos REEE recebidos e/ou gerados pelas empresas estudadas (Figura 5). Pelos resultados, ficou constatado que $40 \%$ das empresas doavam a terceiros, $35 \%$ direcionavam para reciclagem, $5 \%$ entregavam para catadores e $15 \%$ tinham outro destino. Dentre 
os $15 \%$ que assinalaram a opção "outros", destaca-se uma das empresas que realizava a incineração dos resíduos, através da contratação de empresa especializada; outra que direcionava seus resíduos em conjunto com lixo comum, pelo sistema público de coleta da cidade, a URBANA; por último, uma empresa que afirmava não receber resíduos eletrônicos, logo não tinha responsabilidade pelo destino final. A maioria das empresas contava com o serviço de empresas especializadas no tratamento de resíduos eletrônicos, sendo a maior parte localizada fora do Estado do RN.

Contudo, nota-se que os planos de gerenciamento adotados pelas empresas do setor de informática apresentavam, em sua maioria, os requisitos básicos para o adequado gerenciamento de resíduos eletrônicos, por exemplo, práticas de reciclagem interna e área de armazenamento de resíduos, muito embora, na prática, esses planos necessitem de adaptações para serem considerados funcionais e atenderem aos objetivos propostos pela PNRS. Os PGRS's implementados contemplavam práticas de logística reversa, destacando-se a reciclagem externa por meio da qual muitas empresas destinavam seus resíduos para empresas especializadas em reciclagem de eletrônicos. Destacam-se, ainda, algumas dificuldades elencadas pelas empresas na inserção da logística reversa, que se resumiam em desconhecimento de técnicas de recuperação e reciclagem, altos custos, falta de informação e ausência de parcerias com fabricantes.

Levando em consideração o número de empresas entrevistadas (20 empresas) e a quantidade de empresas (8 empresas) que possuem o plano de gerenciamento de resíduos eletrônicos implementado, pode-se perceber que foram poucas as que estiveram atentas às propostas da lei de resíduos sólidos e aos impactos sobre suas empresas. Assim, as empresas em que não foi possível observar práticas ambientais, provavelmente apresentarão maiores dificuldades na implementação de planos de gerenciamento de resíduos eletrônicos. Por fim, a ausência de planos de gerenciamento de resíduos eletrônicos dificulta o fomento da logística reversa e, consequentemente, a adequação da PNRS frente aos resíduos eletrônicos. 
Figura 5 - Variável GES_DFI (destino final dos resíduos eletrônicos)

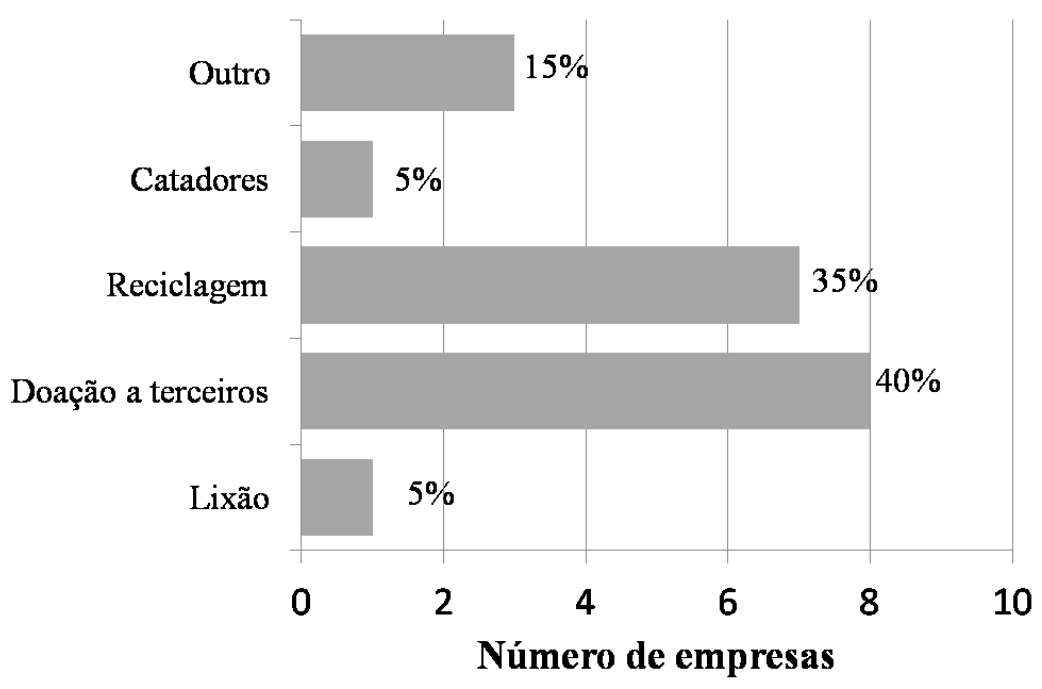

\section{CONSIDERAÇÕES FINAIS}

O estudo limitou-se ao setor de informática na cidade de Natal-RN, abrangendo as empresas do comércio varejista e de assistência técnica. De acordo com os objetivos gerais de diagnosticar a situação do gerenciamento de resíduos de equipamentos eletrônicos oriundos do setor de informática de Natal, foi possível analisar como essas empresas estão se preparando para as adequações impostas pela PNRS, sob a ótica da logística reversa. É possível afirmar que as empresas encontram-se despreparadas em termos de infraestrutura e informação, no que diz respeito ao manejo dos resíduos eletrônicos, uma vez que a maioria das empresas estudadas não possui PGRS ou articulações com fabricantes que possuem políticas de incentivo de retorno dos produtos pós-consumo, de modo que se visualiza pouco movimento no sentido de se adequar.

Outro ponto de destaque é a falta de informação quanto à PNRS, visto que a maioria dos empresários ainda não tem total conhecimento da lei e de seu impacto nos diversos setores do comércio e da indústria. Assim, sem infraestrutura e informação, as empresas do setor de informática em Natal não parecem aptas a absorver tão facilmente as novas medidas impostas, apresentando um perfil 
ambiental bem defasado, com poucas atitudes concretas e ausência de práticas proativas de gestão ambiental.

$\mathrm{Na}$ análise dos dados, foi evidenciado que um dos obstáculos para a adoção de ações ambientais no ambiente corporativo, principalmente a adoção de práticas de gerenciamento adequado de resíduos sólidos, é motivado pelo fato de os empresários acreditarem que os clientes não atribuem importância ao gerenciamento de REEE (65\% da amostra). Esse resultado é preocupante, visto que os clientes são os principais estimuladores do desenvolvimento das empresas em aspectos de qualidade e sustentabilidade. Logo, se o consumidor não pressiona o empresário a adotar medidas sustentáveis, este não se vê empenhado a progredir.

Um dado interessante diz respeito ao responsável pelo recolhimento e tratamento dos resíduos eletrônicos, de modo que $60 \%$ da amostra se incluíram no grupo responsável, fato este que cria expectativas para que estas empresas atuem com empenho e responsabilidade na adequação de seus processos. Em relação ao gerenciamento de resíduos eletrônicos, $40 \%$ das empresas apresentam o plano de gerenciamento implementado e/ou em manutenção, o que indica que os outros $60 \%$ não têm medidas formais de gerenciamento, comprometendo a qualidade do manejo de resíduos. Em termos de destino final, apenas 35\% direcionam os resíduos eletrônicos para a reciclagem, proporcionando o fluxo dos resíduos por mercados secundários.

No decorrer do trabalho, algumas limitações destacaram-se como, por exemplo, a indisponibilidade de algumas empresas para responder o questionário, visto que, da amostra inicial de 30 empresas, apenas 20 se prontificaram a responder. Houve, também, o fato de que algumas empresas optaram por enviar o questionário via correio eletrônico, acarretando, por vezes, atraso na pesquisa, em virtude de questões incompletas, problema resolvido através de solicitações em telefonemas.

Através da análise deste trabalho, pode-se sugerir a realização de pesquisas direcionadas à investigação do comportamento dos consumidores frente à nova lei de resíduos sólidos e suas disponibilidades para contribuir com o novo sistema, baseado na logística reversa; pode-se investigar mais detalhadamente o destino 
final dos resíduos eletrônicos e mercados secundários, além de avaliar a eficiência da política de retorno de resíduos pós-consumo em diversos pontos de coleta.

Em linhas gerais, a realidade do setor de informática, em Natal, reflete até então ausência de políticas públicas, visto que as empresas não apresentam os requisitos básicos para um gerenciamento de resíduos eletrônicos eficiente, com destino adequado e um sistema de logística reversa atuante, de modo a promover a sustentabilidade empresarial.

No entanto, diante da sanção da PNRS, criam-se expectativas para a correta implementação de adaptações no gerenciamento de resíduos, ao passo em que se espera conscientização de consumidores e pressão sobre os integrantes de toda cadeia produtiva.

Para tanto, alguns obstáculos devem ser vencidos como, por exemplo, a disposição de consumidores para contribuir com a logística reversa, retornando seus resíduos em postos de coleta; a adequação dos municípios em um prazo de quatro anos, contando com o fato de que os que não se adequarem correm risco de perder a verba; os custos elevados para os fabricantes, tendo em vista a complexidade do processo e dependência dos consumidores para seu sucesso; e, por fim, a cooperação de governos municipais, estaduais e órgãos ambientais para a completa regulamentação e fiscalização.

\section{REFERÊNCIAS}

ASSOCIAÇÃO BRASILEIRA DE EMPRESAS DE LIMPEZA PÚBLICA E RESÍDUOS ESPECIAIS - ABELPRE. Panorama dos resíduos sólidos no Brasil. São Paulo, 2009. $210 \mathrm{p}$.

BARBIERI, J. C. Gestão ambiental empresarial: conceitos, modelos e instrumentos. São Paulo: Saraiva, 2004. 328 p.

BERNSTAD, A.; JANSEN, J. C.; ASPEGREN, H. Property-close source separation of hazardous waste and waste electrical and electronico equipment : a awedish case study. Waste Management. , v. 31, p. 536-543, 2011.

BRASIL. Lei № 12.305, de 2 de agosto de 2010. Institui a Política Nacional de Resíduos Sólidos; altera a Lei no 9.605, de 12 de fevereiro de 1998; e dá outras 
providências. Disponível em: <http://www.planalto.gov.br/ccivil_03/_ato20072010/2010/lei//12305.htm>. Acesso em: 5 out. 2010.

. Resolução do CONAMA n 23, de 12 de dezembro de 1996. Dispõe sobre as definições e o tratamento a ser dado aos resíduos perigosos, conforme as normas adotadas pela Convenção da Basiléia sobre o controle de Movimentos Transfronteiriços de Resíduos perigosos e seu Depósito. Disponível em: <http://www.mma.gov.br>. Acesso em: 5 de out. 2010.

. Resolução do CONAMA n 401, de 04 de novembro de 2008. Estabelece os limites máximos de chumbo, cádmio e mercúrio para pilhas e baterias comercializadas no território nacional e os critérios e padrões para o seu gerenciamento ambientalmente adequado, e dá outras providências. Disponível em:< http://www.mma.gov.br > Acesso em: 4 de out. 2010.

CALDWELL, B. Reverse Logistics: untapped opportunities exist in returned products, a side of logistics few businesses have thought about-until now. Information Week online, abril, 1999.

CARDOSO, R. Varejo sustentável. GV Executivo, v. 71, n. 5, set./out. 2008.

CHUNG, S.; LAU, K.; ZHANG, C. Generation of and control measures for, ewaste in Hong Kong. Waste management. v. 31, p. 544-554, 2011.

CLOQUELL-BALLESTER, V.; MONTERDE-DÍAZ, R.; CLOQUELL-BALLESTER, V.; TORRES-SIBILLE, A. C. Environmental education for small- and medium-sized enterprises: methodology and e-learning experience in the Valecian region. Journal of Environmental Management., v.87, p.507-520, 2008.

DONAIRE, D. Gestão ambiental na empresa. 2. ed. São Paulo: Atlas, 1999. 169 p.

FUNDAÇÃO ESTADUAL DE MEIO AMBIENTE - FEAM. Diagnóstico da geração de resíduos eletroeletrônicos no Estado de Minas Gerais. Belo Horizonte, 2009

GONÇALVES, M. E.; MARINS, F. A. Logística reversa numa empresa de laminação de vidros: um estudo de caso. Gestão \& Produção. v.13, n.3, p.397-410, set./dez. 2006.

JI, G. Effective implementation of weee take-back directive: what types of take-back network patterns in china. Systems Engineering Procedia, v.2, p.366-381, 2011.

KERR, W.; RYAN, C. Eco-efficiency gains from remanufacturing: a case study of photocopier remanufacturing at Fuji Xerox Australia. Journal of Cleaner

Production. v. 9, p. 75-81, 2001. 
KHETRIWAL, D. S.; KRAEUCHI, P.; WIDMER, R. Producer responsibility for e-waste management: key issues for consideration - learning from the swiss experience. Journal of Environmental, v. 90, p. 153-165, 2009.

LEITE, P. R. Logística reversa: nova área da logística empresarial. Revista Tecnologística. São Paulo: Publicare, maio 2002.

LÓPEZ-GAMERO, M. D.; MOLINA-AZORÍN, J. F.; CLAVER-CORTÉS, E. The potential of environmental regulation to change managerial perception, environmental management, competitiveness and financial performance. Journal of Cleaner Production, v.18, p.963-974, 2010.

MACEDO, L. C. Responsabilidade social empresarial e sustentabilidade na cadeia de valor do varejo. 2007. 61f. Monografia (Curso de Especialização em Gestão de Sustentabilidade) - Fundação Getúlio Vargas, São Paulo, 2007.

MOURA, B. Logística: conceitos e tendências. Portugal: Lisboa, 2006. 352 p.

ONGONDO, F. O.; WILLIAMS, I. D.; CHERRETT, T. J. How are WEEE doing? A global reviem of the management of electrical and electronics wastes. Waste Management v.31, p.714-730, 2011.

RAMPAZZO, L. Metodologia científica: para alunos dos cursos de graduação e pós-graduação. 3 ed. São Paulo: Edições Loyola, 2005.

ROGERS, D. S.; TIBBEN-LEMBKE, R. S. Going backwards: reverse logistics trends and practices. Universidade de Nevada. Reno: Reverse Logistics Executive Council,1998. $283 f$.

SILVA, D.G.K.C. et al. Estudo sobre a percepção ambiental em laboratórios de análises clínicas. Engenharia Ambiental, Espiríto Santo do Pinhal, v.6, n.1. p.154168, jan./abr. 2009.

SILVA, Edna Lúcia; MENEZES, Estera Muszkat. Metodologia da pesquisa e elaboração de dissertação.3 ed. Florianópolis: Laboratório de Ensino a Distância da USFC, 2001. 121 p.

STOCK, J. R; LAMBERT, D. M. Becoming a world class company with logistics service quality. International Journal of Logistics Management, v. 3, n. 7, p. 7381, 1992.

THIERRY, Martijn et al. Strategic issues in product recovery management. California Management Review, v. 37, n.2, 1995.

TRUTTMANN, N.; RECHBERGER, H. Contribution to resource conservation by reuse of electrical and electronic household appliances. Resources Conservation \& Recycling, v.48, p.249-262, 2006. 
UNIÃO EUROPÉIA. Directiva N. ${ }^{\circ}$ 2002/95/CE, do Parlamento Europeu e do Conselho, de 27 de Janeiro de 2003, relativa à restrição do uso de determinadas substâncias perigosas em equipamentos elétricos e eletrônicos. Jornal Oficial da União Européia, L37, 19-23. 2003a.

UNIÃO EUROPÉIA. Directiva Nº 2002/96/CE, do Parlamento Europeu e do Conselho, de 27 de janeiro de 2003, relativa aos resíduos de equipamentos elétrico e eletrônicos (REEE). Jornal Oficial da União Européia, L37, 24-39. 2003b.

UNITED NATIONS ENVIRONMENT PROGRAMME. Recycling: from e-waste to resources. Berlim: UNEP, 2009. 120 p.

VIRGENS, T. A. N. Contribuições para a gestão dos resíduos de equipamentos elétricos e eletrônicos: ênfase nos resíduos pós-consumo de computadores.2009. 198f. Dissertação (Mestrado em Engenharia Ambiental Urbana) - Universidade Federal da Bahia, Salvador, 2009.

WIDMER, R.; OSWALD-KRAPF, H.; SINHA-KHETRIWAL, D.; SCHNELLMANN, M.; BONI, H. Global perspectives on e-waste. Environmental Impact Assessment Review, v. 25, p.436-458, 2005.

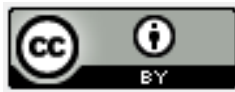

Artigo recebido em 31/10/2011 e aceito para publicação em 24/01/2012. 